\title{
LFA-1-specific therapy prolongs allograft survival in rhesus macaques
}

\author{
Idelberto R. Badell, ${ }^{1}$ Maria C. Russell,, ${ }^{1}$ Peter W. Thompson, ${ }^{1}$ Alexandra P. Turner, ${ }^{1}$ \\ Tim A. Weaver, ${ }^{1}$ Jennifer M. Robertson, ${ }^{1}$ Jose G. Avila, ${ }^{1}$ Jose A. Cano, ${ }^{1}$ Brandi E. Johnson, ${ }^{1}$ \\ Mingqing Song, ${ }^{1}$ Frank V. Leopardi, ${ }^{1}$ Sarah Swygert, ${ }^{1}$ Elizabeth A. Strobert, ${ }^{2}$ \\ Mandy L. Ford, ${ }^{1}$ Allan D. Kirk, ${ }^{1}$ and Christian P. Larsen ${ }^{1}$
}

${ }^{1}$ Emory Transplant Center and ${ }^{2}$ Yerkes National Primate Research Center, Emory University, Atlanta, Georgia, USA.

\begin{abstract}
Outcomes in transplantation have been limited by suboptimal long-term graft survival and toxicities associated with current immunosuppressive approaches. $T$ cell costimulation blockade has shown promise as an alternative strategy to avoid the side effects of conventional immunosuppressive therapies, but targeting CD28-mediated costimulation alone has proven insufficient to prevent graft rejection in primates. Donor-specific memory $T\left(T_{M}\right)$ cells have been implicated in costimulation blockade-resistant transplant rejection, due to their enhanced effector function and decreased reliance on costimulatory signaling. Thus, we have tested a potential strategy to overcome $T_{M}$ cell-driven rejection by targeting molecules preferentially expressed on these cells, such as the adhesion molecule lymphocyte function-associated antigen 1 (LFA-1). Here, we show that short-term treatment (i.e., induction therapy) with the LFA-1-specific antibody TS-1/22 in combination with either basiliximab (an IL-2R $\alpha$-specific $\mathrm{mAb}$ ) and sirolimus (a mammalian target of rapamycin inhibitor) or belatacept (a high-affinity variant of the CD28 costimulation-blocker CTLA4Ig) prolonged islet allograft survival in nonhuman primates relative to control treatments. Moreover, TS-1/22 masked LFA-1 on $T_{M}$ cells in vivo and inhibited the generation of alloproliferative and cytokine-producing effector $T$ cells that expressed high levels of LFA-1 in vitro. These results support the use of LFA-1-specific induction therapy to neutralize costimulation blockade-resistant populations of T cells and further evaluation of LFA-1-specific therapeutics for use in transplantation.
\end{abstract}

\section{Introduction}

$\mathrm{T}$ cells play a central role in the initiation of allograft rejection. As a result, immunosuppressive agents that selectively target molecules critical to $\mathrm{T}$ cell activation have the potential for preventing allograft rejection, with a reduced risk of the side effects typically associated with non-T cell specific therapies. In general, optimal naive $T$ cell activation requires TCR binding to donor antigen (signal 1) in the context of either self or allogeneic MHC molecules (1) and a subsequent costimulatory signal (signal 2) (2). Soluble factors, such as cytokines, deliver additional stimuli (signal 3) to augment the $\mathrm{T}$ cell response (3). This 3 -signal model of naive $\mathrm{T}$ cell activation has served as a useful conceptual framework for the development of novel strategies to combat rejection in allotransplantation. However, recent recognition that non-naive or memory $\mathrm{T}\left(\mathrm{T}_{\mathrm{M}}\right)$ cells have less demanding requirements for activation, such as a reduced signal 1 threshold and decreased reliance on signal 2 (4), has forced an expanded approach that not only addresses control of de novo $\mathrm{T}$ cell activation but also limits the deployment of $\mathrm{T}$ cells with prior antigen experience. This is particularly true when replacing immunosuppressants targeting ubiquitous cellular processes with biologics targeting lymphocyte-specific molecules. For instance, specific targeting of T cell costimulation has the potential to create a gap in immune coverage by failing to prevent rejection driven by relatively costimulation blockade-resistant $T_{M}$ cells $(5,6)$. As such, we have pursued alternative targets to specifically neutralize resistant $\mathrm{T}$ cell populations that threaten graft survival, without resorting to broad

Conflict of interest: The authors have declared that no conflict of interest exists. Citation for this article: J Clin Invest. 2010;120(12):4520-4531. doi:10.1172/JCI43895. immune suppression. As an example, we have demonstrated that selective depletion of $\mathrm{T}_{\mathrm{M}}$ cells using a $\mathrm{CD}$ 2-specific fusion protein helps prevent costimulation blockade-resistant renal allograft rejection in nonhuman primates (NHPs) (7).

One candidate molecule with potential to control $\mathrm{T}_{\mathrm{M}}$ cell-mediated rejection is the adhesion molecule lymphocyte function-associated antigen 1 (LFA-1), originally described as a cell surface protein critical for cytolytic T cell killing (8). LFA- 1 is a $\beta_{2}$ integrin heterodimer, composed of a unique $\alpha$ chain (CD11a) and a shared $\beta$ chain (CD18) that primarily binds ICAM-1. Initial studies linked its immunologic importance to its role in facilitating intercellular leukocyte interactions and trafficking, although more current work has highlighted expanded functions to include dynamic optimization of the immunologic synapse and $\mathrm{T}$ cell activation and costimulatory signaling (9). LFA-1 has also been recently implicated in the programming of $\mathrm{CD}^{+} \mathrm{T}$ cell memory via ICAM-1 on dendritic cells (10). These multiple mechanisms of action have sustained an interest in LFA-1 as an attractive immunosuppressive target, despite conflicting results from historic preliminary clinical transplant trials (11). Indeed, more recent experience has shown therapy with the LFA-1-specific $\mathrm{mAb}$ efalizumab to be an effective means of controlling the T cell-mediated autoimmune disease psoriasis (12), and its success in this clinical venue has rekindled interest in its use for transplantation.

Experimental outcomes with LFA-1-specific mAbs in transplantation have been promising and have substantiated the resurgent interest in adhesion molecule blockade. Numerous preclinical studies in rodents have demonstrated that LFA-1-specific immune modulation can have a major impact on allogeneic and xenogeneic graft survival and, in some instances, can promote donor- 


\section{A}
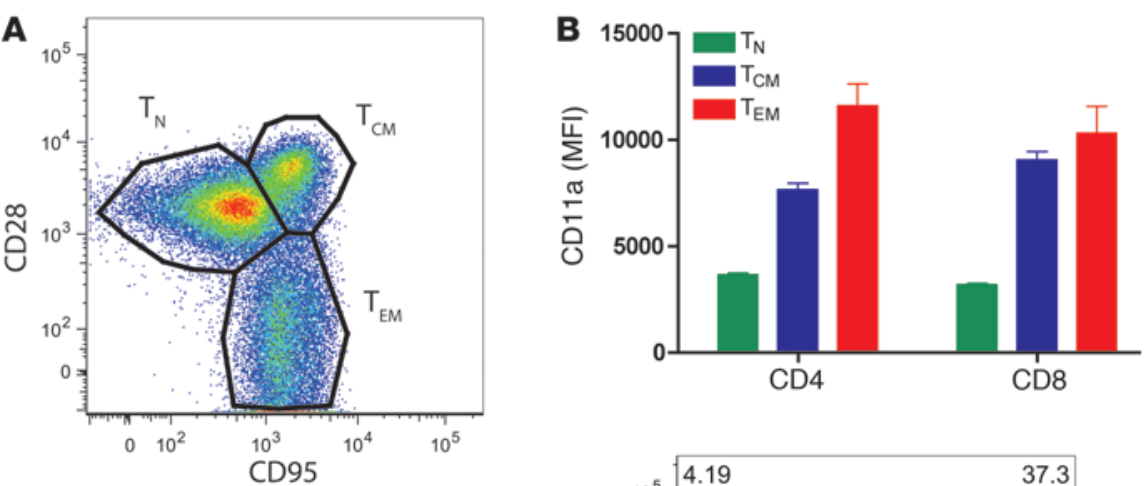

C

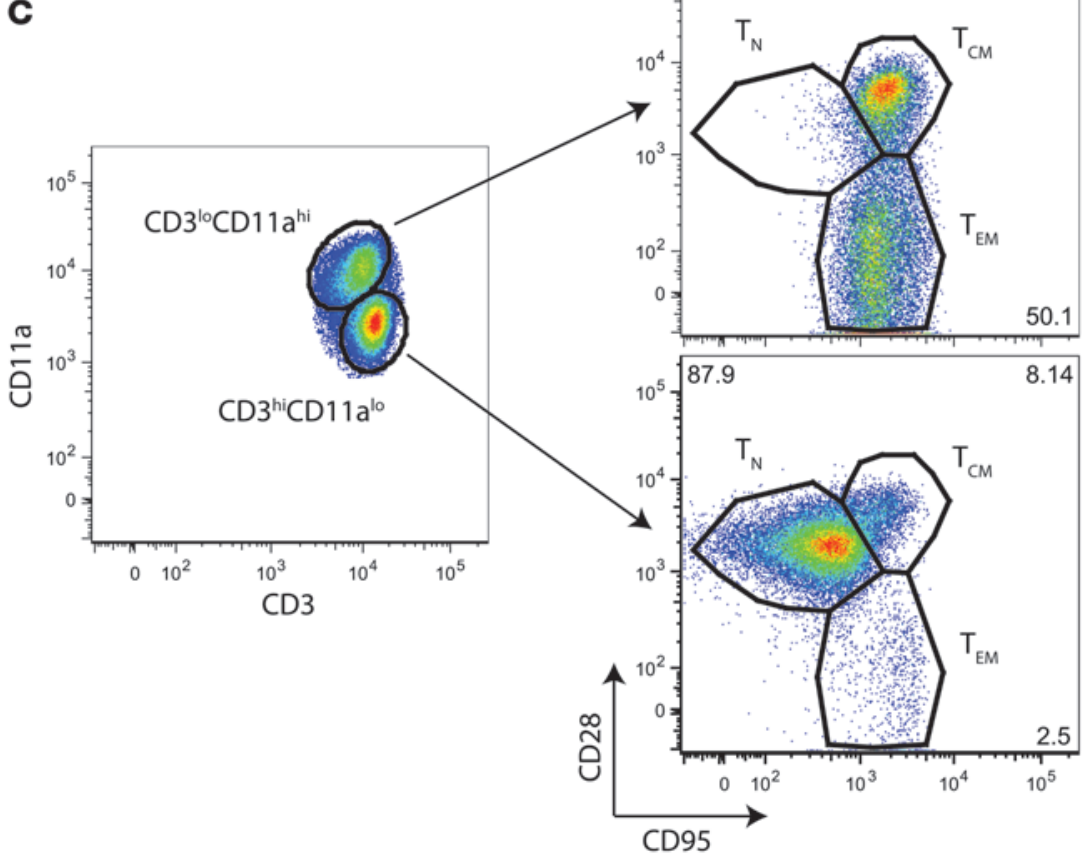

\section{Figure 1}

LFA-1/CD11a is upregulated on rhesus $T_{M}$ cells relative to $T_{N}$ cells. (A) PFC analysis of naive rhesus peripheral blood was used to define and characterize the following $T$ cell subsets: CD28+CD95- $\left(T_{N}\right), C^{+} 28^{+}{ }^{+} D 95^{+}$ $\left(\mathrm{T}_{\mathrm{CM}}\right)$, and CD28-CD95+ ( $\left.\mathrm{T}_{\mathrm{EM}}\right)$. (B) Assessment of untreated macaque lymphocytes $(n=6)$ for LFA-1/CD11a MFI on $\mathrm{CD}^{+}$and CD8 ${ }^{+}$subsets showed increased expression on $T_{M}\left(T_{C M}+T_{E M}\right)$ compared with that of $T_{N}$ cells. (C) Representative $T$ cells have an inverse CD3 and CD11a bimodal distribution, where $C D 3^{\text {hi }} C D 11 a^{\text {lo }}$ cells are largely $C D 28^{+}$ $\mathrm{T}_{\mathrm{N}}$ and $\mathrm{CD} 3^{\mathrm{lo}} \mathrm{CD} 11 \mathrm{a}^{\text {hi }}$ cells are predominantly CD28- $T_{E M}$. $T_{C M}$ segregate less clearly by these parameters. Plot numbers represent the percentage of $T_{N}, T_{C M}$, and $T_{E M}$ cells. PFC plots depicted are of $\mathrm{CD} 3^{+} \mathrm{CD} 8^{+} \mathrm{T}$ cells, representative of both $\mathrm{CD}^{+}$and $\mathrm{CD} 8^{+}$cells. Data represent mean \pm SEM. specific tolerance (9). Moreover, pilot clinical trials in kidney and islet cell transplantation, combining efalizumab with calcineurin inhibitor-sparing (CNI-sparing) immunosuppressive regimens, have suggested efficacy without substantial off-target toxicity (13, 14). Nevertheless, further investigation of LFA-1-based therapy is needed to better elucidate its use. With the exception of 2 studies reporting that $\mathrm{CD} 11 \mathrm{a}$-specific $\mathrm{mAbs}$ can effect modest protection of skin and cardiac allografts in monkeys $(15,16)$, LFA-1 blockade has had little preclinical evaluation in relevant NHP models of transplantation. Importantly, its role as an adjuvant to costimulation blockade remains untested.

For this study, we have evaluated TS-1/22, a mouse anti-human CD11 a mAb that has been shown to inhibit T cell-mediated cytolysis (17). We have phenotypically and functionally characterized the role of LFA-1 blockade in rhesus monkey alloimmune and viral-specific responses, specifically showing that LFA-1 is increasingly expressed on $\mathrm{T}_{\mathrm{M}}$ cells. We also have tested TS-1/22-based regimens for their efficacy in preventing allograft rejection in a rhesus macaque model of pancreatic islet cell transplantation. We find that TS-1/22 in combination with either signal 2 or signal 3 blockade significantly prolongs allograft survival, possibly by the preferential suppression of alloreactive effector and $\mathrm{T}_{\mathrm{M}}$ cells dense in LFA-1.

\section{Results}

LFA-1 is preferentially expressed on rhesus $T_{M}$ cells. The differential tissue and cellular distributions of LFA-1, as described in mice and subsequently in humans, have suggested this molecule as a potential therapeutic target on cytotoxic $\mathrm{T}$ cells for cell-mediated immunity (18). We therefore used polychromatic flow cytometry (PFC) to assess the surface density of LFA-1 (specifically CD11a) on untreated rhesus PBLs, including naive $\left(\mathrm{T}_{\mathrm{N}}\right)$ and $\mathrm{T}_{\mathrm{M}}$ cell subsets (ref. 19 and Figure 1A). Consistent with mouse and human lymphoid phenotypes, LFA-1 was preferentially expressed on $T_{M}$ $\left(\mathrm{CD} 28^{+/-} \mathrm{CD} 95^{+}\right)$compared with $\mathrm{T}_{\mathrm{N}}\left(\mathrm{CD} 28^{+} \mathrm{CD} 95^{-}\right)$cells (Figure 1B). CD11a levels were highest on the $\mathrm{T}$ effector memory $\left(\mathrm{T}_{\mathrm{EM}}\right.$; $\mathrm{CD} 28^{-} \mathrm{CD} 5^{+}$) compartment of both $\mathrm{CD}^{+}$and $\mathrm{CD} 8^{+} \mathrm{T}$ cells. Interestingly, CD2 $8^{+} \mathrm{T}_{\mathrm{N}}$ cells were overwhelmingly CD $3{ }^{\mathrm{hi}} \mathrm{CD} 11 \mathrm{a}^{\mathrm{lo}}$, while $\mathrm{CD} 28^{-} \mathrm{T}_{\mathrm{EM}}$ cells were conversely $\mathrm{CD} 3{ }^{\text {lo }} \mathrm{CD} 11 \mathrm{a}^{\text {hi }}$ (Figure $1 \mathrm{C}$ ).

TS-1/22 inhibits proliferation of alloreactive T cells that express high levels of LFA-1. To investigate the effect of TS-1/22 on alloreactivity, we used mixed lymphocyte cultures (MLCs) to evaluate the relationship between alloresponsive $T$ cells and their surface expression of LFA-1 in vitro. Responder lymphocytes were labeled with CFSE to facilitate the assessment of LFA-1 on specific generations of dividing alloreactive cells identified by the dilution of CFSE fluorescence 

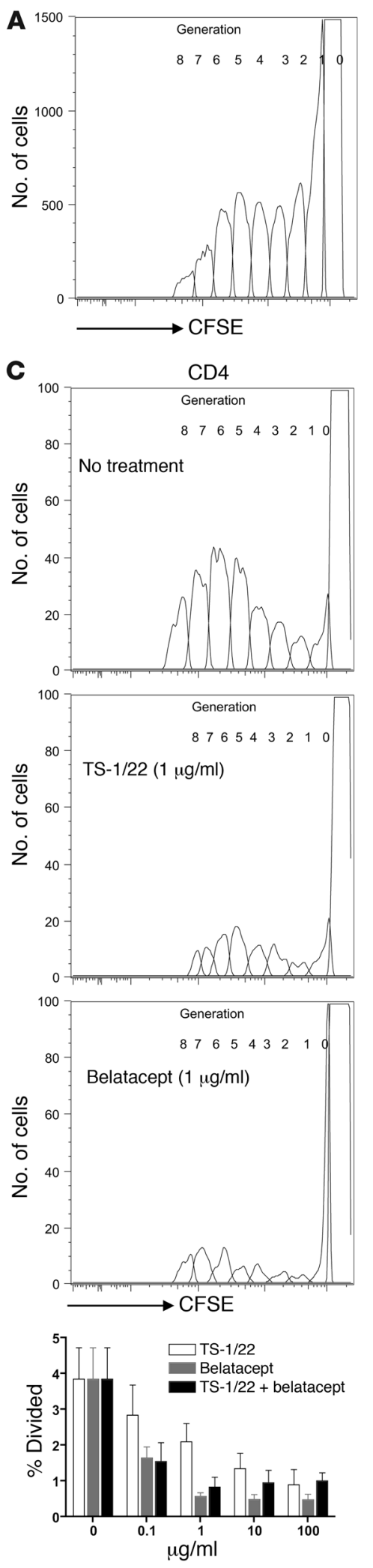

B
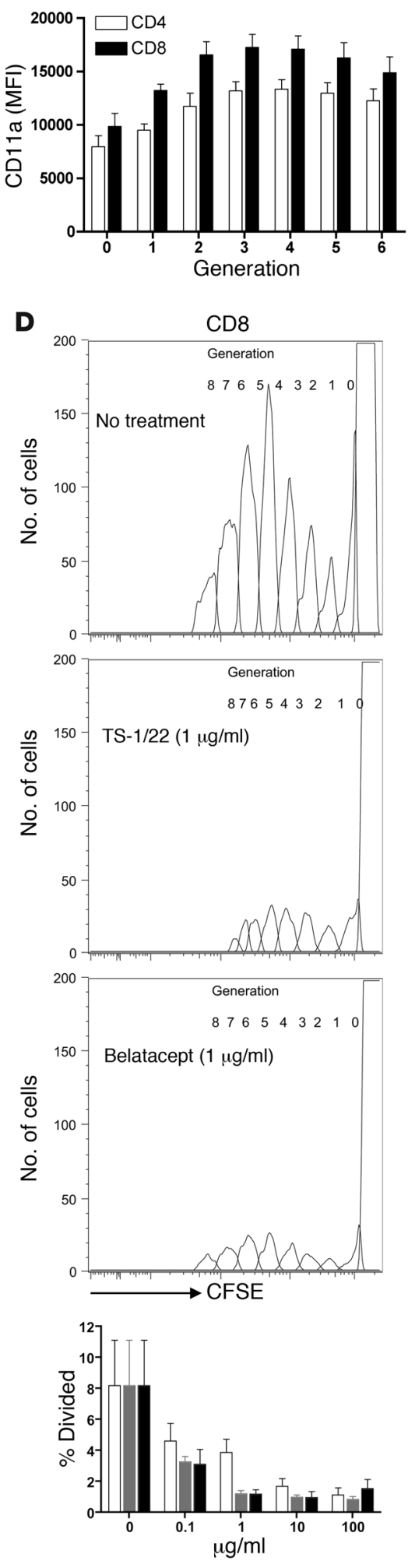

Figure 2

TS-1/22 inhibits the generation of CD11 $\mathrm{a}^{\text {hi }}$ alloreactive $T$ cells. CFSE-labeled responder T cells were allostimulated in MLCs and analyzed after 5 days of culture using PFC. (A) Progressive generations of alloreactive T cells lose CFSE intensity with each division, allowing for their distinction from undivided cells (generation 0 ) and the evaluation of each individual generation for CD11a expression. (B) Increasing generations of alloresponsive $\mathrm{CD}^{+}$and $\mathrm{CD} 8^{+} \mathrm{T}$ cells progressively upregulated LFA-1/CD11a $(n=5)$. (C) CD4+ and (D) CD8 ${ }^{+}$T cell alloreactivity was blunted in the presence of TS-1/22 or belatacept in comparison with reactivity without blockade. The lower bar graphs depict dose-dependent inhibition of the percentage of dividing alloreactive T cells $(n=3)$. Data represent mean \pm SEM.

presence of varying doses of TS- $1 / 22$ and belatacept, a high-affinity variant of the CD28/CD80/86 costimulation blocker CTLA4Ig. LFA-1 and CD28 blockade independently inhibited alloreactive $\mathrm{CD}^{+}$and $\mathrm{CD}^{+} \mathrm{T}$ cell proliferation in a dose-dependent manner across a concentration range of 4 logs (Figure 2, $\mathrm{C}$ and $\mathrm{D})$. Despite the individual antiproliferative effect of each reagent, the combination of TS-1/22 and belatacept did not have an additive or synergistic effect on $\mathrm{T}$ cell proliferation in response to alloantigen stimulation (Figure 2, C and D).

TS-1/22 abrogates antigen-specific T cell differentiation into cytokine-producing effectors that express high levels of LFA-1. Having observed elevated levels of LFA-1 on $\mathrm{T}_{\mathrm{M}}$ cells and highly alloresponsive $\mathrm{CD}^{+}$and $\mathrm{CD}^{+} \mathrm{T}$ cells, we sought to functionally characterize CD11a expression on cytokine-secreting cells. Rhesus lymphocytes were allostimulated in MLCs, after which intracellular IFN- $\gamma$-staining techniques were used to distinguish cytokine-producing cells from non-producers using PFC analysis. Similar to the augmentation of CD11a concentration on $\mathrm{T}$ cells proliferating in response to alloantigen (Figure 2), IFN- $\gamma$ producers exhibited increased surface expression of LFA-1 relative to that of IFN- $\gamma^{-}$cells (Figure 3A). The increase in CD11a expression on alloantigen-stimulated $\mathrm{CD}^{+}$and $\mathrm{CD}^{+} \mathrm{T}$ cells paralleled their acquisition of IFN- $\gamma$ secretory capacity, suggesting a role for LFA-1 in the physiologic generation of cytokine-producing effector $\mathrm{T}$ cell responses. To test this possibility in a model of protective immunity, lymphocytes isolated from rhesus monkeys previously immunized with vaccinia virus (VV) and boosted with modified vaccinia Ankara virus (MVA) were incubated with VV lysates in the presence or absence of anti-LFA-1 or CD28 costimulation blockade. TS-1/22 blocked the formation of antigen-specific IFN- $\gamma$ - and TNF- $\alpha$-producing $\mathrm{T}$ cells compared with that of untreated and belataafter each cell division (Figure 2A). CD11a surface density increased on successive generations of dividing $\mathrm{CD}^{+}$and $\mathrm{CD}^{+} \mathrm{T}$ cells (Figure $2 \mathrm{~B}$ ), covering the surface of these highly responsive cells with an attractive therapeutic target. We then performed MLCs in the cept-treated samples (Figure 3B). This dose-dependent inhibition was greatest on dual (IFN- $\left.\gamma^{+} \mathrm{TNF}-\alpha^{+}\right) \mathrm{CD}^{+}$and $\mathrm{CD} 8^{+}$cytokine secretors, cells previously shown to be more potent effectors than less differentiated monofunctional (IFN- $\gamma^{-}$TNF- $\alpha^{+}$or IFN- $\gamma^{+}$TNF- $\alpha^{-}$) 

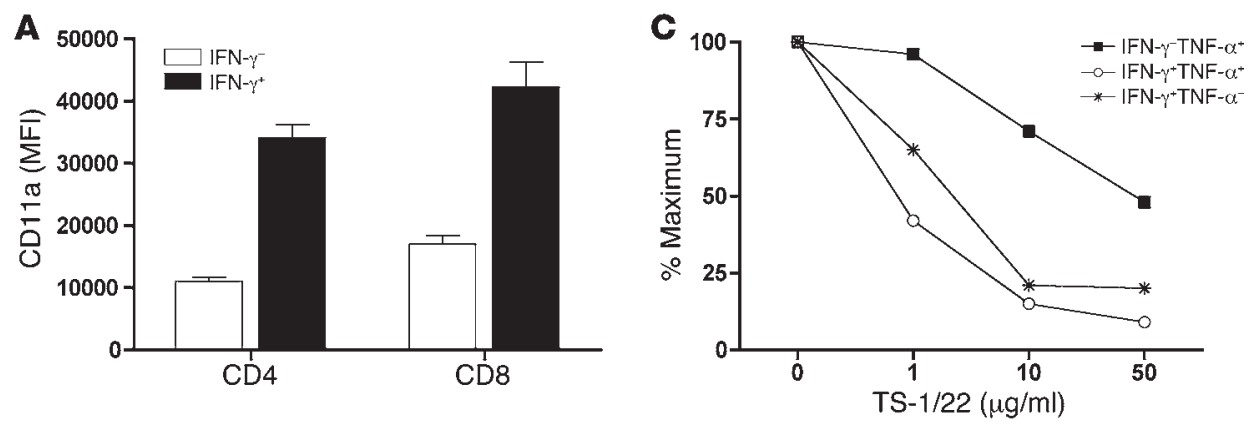

B

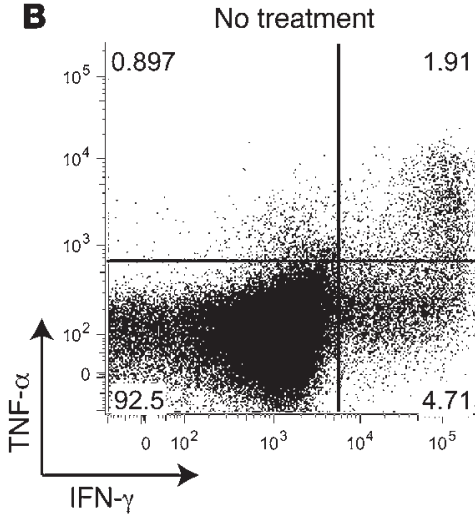

TS-1/22 (10 $\mu \mathrm{g} / \mathrm{ml})$

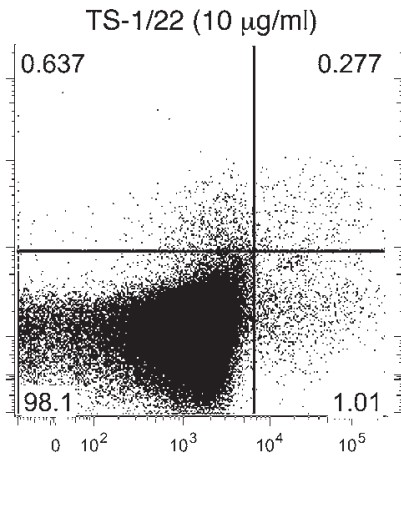

Figure 3

TS-1/22 inhibits T cell differentiation into CD11 ahi cytokine-producing effectors. CFSE MLCs were used to determine the relationship between LFA-1 and cytokine-secreting T cells, using intracellular staining techniques and PFC. (A) Allostimulation of responder lymphocytes demonstrated that CD4 ${ }^{+}$and $\mathrm{CD}^{+}$ $\mathrm{T}$ cell IFN- $\gamma$ production mirrored an increase in CD11a surface density, as IFN- $\gamma^{+}$responder lymphocytes expressed large amounts of CD11a on their surfaces. This was in contrast to IFN- $\gamma^{-}$cells $(n=5)$. (B) Lymphocytes from monkeys immunized with VV and boosted with MVA upon VV lysate challenge displayed impaired differentiation of T cells into IFN- $\gamma-$ and/or TNF- $\alpha-$ secreting cells in the presence of TS-1/22. This was in contrast to untreated and belatacept-treated samples. CD3+CD8+ PFC plots shown are representative of $\mathrm{CD} 4^{+}$and $\mathrm{CD} 8^{+} \mathrm{T}$ cells. Plot numbers represent the percentage of cells in each corresponding quadrant. (C) This effect was dose dependent and greatest on dual (IFN- $\gamma^{+}$TNF- $\alpha^{+}$) cytokine-producers (data are representative of 2 independent experiments). The percentage maximum was calculated relative to an untreated control. Data represent mean $\pm \mathrm{SEM}$.

$\mathrm{T}$ cells (ref. 20 and Figure 3C). Importantly, additional mAbs or fusion proteins that block costimulatory signals (CD28, CD40, and CD154) and signal 3 (IL-2R) did not have this effect (data not shown), suggesting the potential for LFA-1-directed therapy as an adjunct to other biologics.

Anti-LFA-1 induction plus signal 3 blockade prolong islet allograft survival. Based on the favorable cellular distribution of LFA-1 and the ability of anti-LFA-1 therapy to attenuate alloreactive effector $\mathrm{T}$ cell responses, we set out to evaluate TS-1/22 in combination with 2 immunosuppressive strategies in a clinically relevant NHP model of allotransplantation (Table 1). We chose pancreatic islet transplantation, given the clear need to develop nondiabetogenic alternatives to currently available regimens (21). To first determine the efficacy of LFA-1 blockade on allograft survival in vivo, we combined TS-1/22 with 2 signal 3-specific agents: basiliximab, an anti-IL-2R $\alpha \mathrm{mAb}$, and sirolimus, a mammalian target of rapamycin (mTOR) inhibitor.

LFA-1 blockade has been shown to impair NK cell cytotoxicity and cytotoxic $\mathrm{T}$ lymphocyte function in response to viral pathogens $(22,23)$. Taken together with our data indicating that VV-spe-

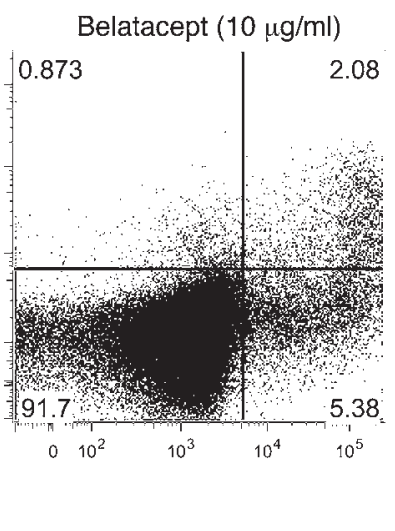

cific responses were impaired by TS-1/22, we considered LFA-1specific therapy to have the potential to beneficially suppress allograft rejection, yet concurrently compromise protective immunity. As such, we administered TS-1/22, as a short-term induction agent, in the hopes of garnering its immunosuppressive potential, while minimizing the risk of infection.

Rhesus macaques were given streptozocin (STZ) to induce diabetes and underwent i.v. glucose tolerance testing (IVGTT) to confirm the absence of glycemic control and C-peptide production prior to islet cell transplantation (data not shown). Recipient monkeys were intraportally transplanted with allogeneic islets $(>10,000$ islet equivalents $/ \mathrm{kg}$ [IEQs/kg]) from MHC-mismatched donors and immunosuppressed with TS-1/22 induction plus basiliximab and sirolimus maintenance therapy (Figure 4A). All animals receiving this regimen (group 1) experienced an immediate return to euglycemia after transplant, and 4 out of 5 had prolonged islet allograft survival (Figure 4, B and C). In contrast, controls treated with TS-1/22 alone (group 3) or basiliximab and sirolimus (group 4) rejected shortly after transplant, despite islet engraftment and resolution of hyperglycemia (Figure 4, D and E). Daily fasting blood glucose (FBG) levels and periodic glucose tolerance tests with C-peptide measurements confirmed glycemic control and graft function in surviving islet allograft recipients (Figure $4 \mathrm{C}$ and data not shown).

One group 1 monkey (RWi11) required euthanasia on postoperative day (POD) 17, secondary to weight loss and failure to thrive, in spite of normoglycemia and insulin independence. RWi11 experienced more than $15 \%$ weight loss immediately after STZ prior to transplant or the administration of TS-1/22, compromising his capacity to tolerate further interventions. Histologic examination at necropsy revealed the presence of viable islets in the liver that were free of lymphocytic infiltrates and strong insulin positivity using immunohistochemical staining (data not shown), indicating that this animal was not undergoing immunologic rejection.

Notably, TS-1/22 induction therapy facilitated islet allograft survival for more than 375 and 371 days in two group 1 animals. These 2 long-term survivors were sacrificed at more than 1 year after transplant with functioning grafts, as evidenced by their daily FBG levels and maintenance of glycemic control in response to glucose tolerance testing (Figure 4C and data not shown). Histologic 
Table 1

Recipient groups and islet allograft survival

\begin{tabular}{|c|c|c|c|c|}
\hline Group & Therapy & Recipient ID & IEQ/kg & $\begin{array}{c}\text { Graft } \\
\text { survival (d) }\end{array}$ \\
\hline $1(n=5)$ & $\begin{array}{c}\text { TS-1/22 } \\
\text { Basiliximab } \\
\text { Sirolimus }\end{array}$ & $\begin{array}{l}\text { RWi11A } \\
\text { RVh11 } \\
\text { RIr11 } \\
\text { RL011 } \\
\text { RAp11 }\end{array}$ & $\begin{array}{l}21,741 \\
11,816 \\
22,088 \\
22,485 \\
12,549\end{array}$ & $\begin{array}{c}>17 \\
154 \\
>375 \\
>371 \\
67\end{array}$ \\
\hline $2(n=5)$ & $\begin{array}{c}\text { TS-1/22 } \\
\text { Belatacept }\end{array}$ & $\begin{array}{l}\text { RLn11 } \\
\text { RDp11 } \\
\text { RGm11 } \\
\text { RNw11 } \\
\text { RHu11 }\end{array}$ & $\begin{array}{l}12,269 \\
12,269 \\
14,321 \\
16,521 \\
16,521\end{array}$ & $\begin{array}{c}>367 \\
223 \\
>373 \\
73 \\
338\end{array}$ \\
\hline $3(n=2)$ & TS-1/22 & $\begin{array}{l}\text { RPp11 } \\
\text { Rlg12 }\end{array}$ & $\begin{array}{l}13,668 \\
16,243\end{array}$ & $\begin{array}{l}10 \\
12\end{array}$ \\
\hline $4(n=3)$ & $\begin{array}{c}\text { Basiliximab } \\
\text { Sirolimus }\end{array}$ & $\begin{array}{l}\text { RQz6B } \\
\text { Rlb7B } \\
\text { RMc11 }\end{array}$ & $\begin{array}{l}12,980 \\
10,903 \\
13,796\end{array}$ & $\begin{array}{c}8 \\
8 \\
10\end{array}$ \\
\hline $5(n=3)$ & Belatacept & $\begin{array}{c}\text { Rlt7c } \\
\text { RKu7c } \\
\text { RDh12 }\end{array}$ & $\begin{array}{c}>10,000 \\
>10,000 \\
17,256\end{array}$ & $\begin{array}{c}58 \\
60 \\
8\end{array}$ \\
\hline
\end{tabular}

AFailure to thrive; Bhistorical control (41); Chistorical control (42).

analysis of their livers showed strongly insulin- and glucagon-positive islets, absent any mononuclear cells, strikingly unlike the dense focal lymphocytic infiltrates and islet destruction observed in the setting of graft rejection (Figure 5). Detailed immunophenotypic analysis of insulitis lesions in rejecting animals showed no differences in infiltrates among treatment groups (data not shown).

To ensure that glycemic control in islet recipients was not due to native islet regeneration, histologic assessments were performed. Examination of group 1-recipient pancreases at termination showed rare insulin-positive $\beta$ cells, incompatible with glucose homeostasis (data not shown), whereas long-term survivor livers revealed intact, undamaged allografted islets (Figure 5). These findings indicate that the lasting insulin independence in recipients achieving 1-year survival was due to transplanted islets and not regenerated native tissue.

LFA-1-specific induction plus costimulation blockade promote islet allograft survival. Costimulatory pathway blockade has long proven capable of allograft protection and, in some instances, tolerance induction in rodent models (24); however, this strategy alone has been less effective in primates, including humans (25). Among several existing hypotheses for this difference, alloreactive $T_{M}$ cellmediated costimulation blockade-resistant rejection has been well described (4). Thus, in an attempt to use LFA-1-specific therapy to overcome $\mathrm{T}_{\mathrm{M}}$ cell-driven costimulation blockade resistance in our rhesus macaque model, we combined TS-1/22 with belatacept. This approach not only interferes with costimulation-dependent CD28 ${ }^{+} \mathrm{CD} 11 \mathrm{a}^{\text {lo }} \mathrm{T}_{\mathrm{N}}$ cells but more specifically provides adjuvant targeting of signal 2 -independent CD $11 \mathrm{a}^{\text {hi }} \mathrm{T}_{\mathrm{M}}$ cells, including CD28-CD11a hi $\mathrm{T}_{\mathrm{EM}}$ cells.

Five additional diabetic rhesus monkeys were transplanted with MHC-mismatched allogeneic islets (>10,000 IEQ/kg) under cover of TS-1/22 induction and CD28-costimulation blockade maintenance therapy (group 2; Figure 6A). All recipients treated with TS-1/22 and belatacept experienced immediate diabetes reversal and extended islet allograft survival (Figure 6, B and C), while controls treated with TS-1/22 alone (group 3) or belatacept alone (group 5) experienced rejection soon after transplant, regardless of adequate islet engraftment (Figure 6, D and E). Daily FBG levels, glucose tolerance testing, and C-peptide production verified allograft function (Figure 6C and data not shown).

Similar to group 1, 2 out of 5 TS-1/22- and belatacept-treated animals achieved more than 1 -year allograft survival with functioning islets. Histology and immunohistochemistry results were consistent with our metabolic observations that healthy donor islets were embedded in the liver parenchyma without lymphocytic destruction (Figure 5). Transplanted $\alpha$ and $\beta$ islet cells stained intensely for glucagon and insulin, respectively. In rejecting animals, no immunophenotypic differences were observed between groups (data not shown).

TS-1/22 binds LFA-1 in vivo. Serial pharmacodynamic monitoring of TS-1/22-treated recipients was performed using PFC to characterize TS-1/22 activity in vivo. $\mathrm{CD}^{+} \mathrm{T}$ cell LFA- 1 receptor occupancy was achieved in TS-1/22-treated animals, as determined by CD11a MFI using a competitive binding assay; detectable LFA-1 was substantially greater before treatment than while on TS-1/22 (Figure 7A). Staining of lymphocytes from animals receiving TS- $1 / 22$ for mouse IgG1 showed the presence of $\mathrm{mAb}$ on the surface of CD11a-bearing cells, indicating that in effect, TS-1/22 did not kill LFA-1-expressing cells or induce LFA-1 internalization; rather, it coated targeted cells and promoted steric inhibition of LFA-1-ligand interactions (Figure 7B). Importantly, CD11a was masked on all CD4 ${ }^{+}$and CD8 ${ }^{+}$ $\mathrm{T}$ cell subsets, including those critical for mediating costimulation blockade-resistant rejection (5-7) (Figure 7C). This effect was dose dependent and resolved upon discontinuation of TS-1/22.

TS-1/22 induces a peripheral lymphocytosis. The administration of TS-1/22 to rhesus macaques did not cause depletion of circulating lymphocytes. On the contrary, examination of the various leukocyte lineages using PFC in TS-1/22-treated monkeys demonstrated a dose-dependent lymphocytosis that resolved after cessation of therapy in comparison with that of controls (Figure 8). This elevation in absolute $\mathrm{T}$ and $\mathrm{B}$ cell numbers was not limited to lymphocytes but rather all LFA-1-expressing leukocytes, including neutrophils and monocytes. $\mathrm{CD}^{+}$and $\mathrm{CD}^{+} \mathrm{T}$ cell subset analysis also showed relative increases in circulating counts (data not shown). Although absolute numbers of cells increased in animals receiving TS- $1 / 22$, there were no consistent alterations in the relative composition of blood lymphocytes.

LFA-1/CD28 blockade prevents donor-specific antibody formation. To assess whether anti-LFA-1-treated animals developed donor-specific antibodies (DSAs) after islet transplantation, we incubated recipient serum with donor lymphocytes and used PFC to detect for alloantibody production. Results showed that the two group 1 recipients experiencing graft rejection formed DSAs (Figure 9, A and B). Interestingly, of the 2 long-term survivors sacrificed with intact graft function, 1 developed anti-donor antibodies upon termination of sirolimus therapy (POD 180), whereas the other had not by POD 371 (Figure 9B). Alternatively, none of the group 2 monkeys receiving TS- $1 / 22$ and belatacept generated DSAs, irrespective of allograft rejection or survival (Figure 9, C and D).

Anti-LFA-1-based regimens do not impair primate health. Quantitative real-time PCR was used to serially monitor the maintenance of immunity against 3 viral pathogens relevant to transplantation, for which all recipients were seropositive before transplant: rhesus cytomegalovirus (rhCMV), simian virus 40 (SV40), and rhesus lympho- 
A

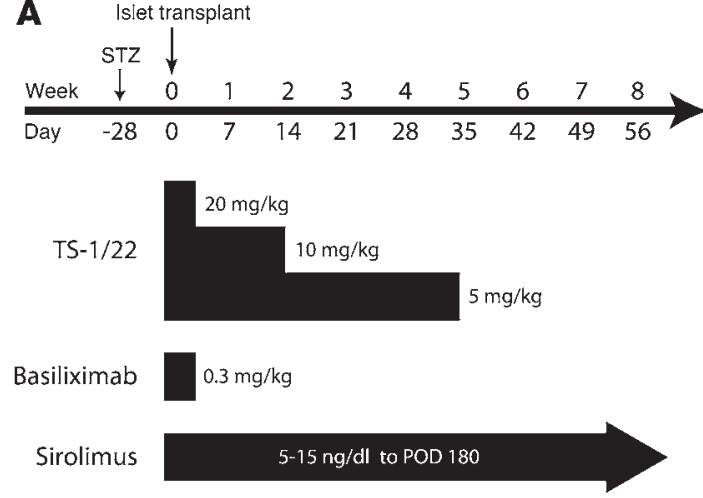

B

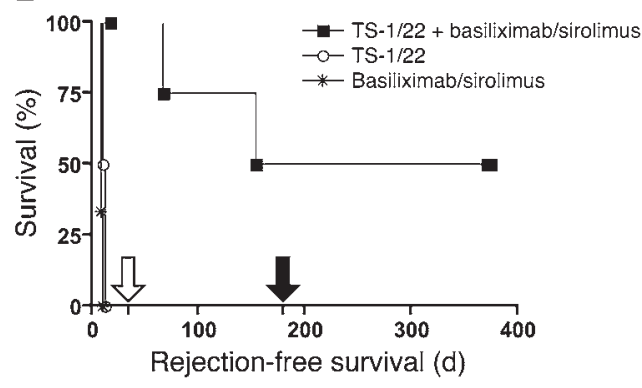

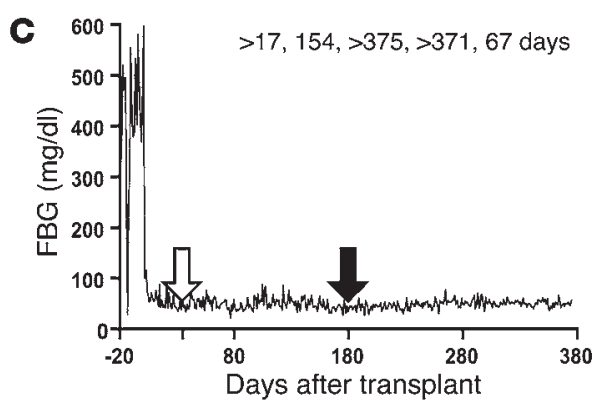
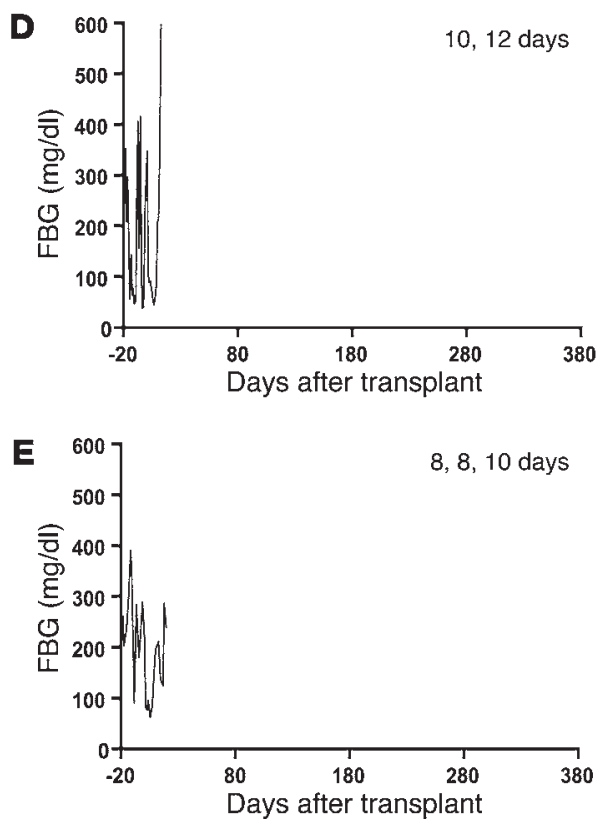

\section{Figure 4}

TS-1/22 plus basiliximab and sirolimus prolongs islet allograft survival. (A) The experimental design is shown. Diabetic rhesus monkeys were transplanted with allogeneic islets and received TS-1/22 induction alone, basiliximab and sirolimus, or TS-1/22 plus basiliximab and sirolimus. After islet engraftment, rejection was defined as FBG of more than $130 \mathrm{mg} / \mathrm{dl}$ on 2 consecutive days. (B) Recipients treated with TS-1/22 induction plus basiliximab and sirolimus (filled squares) experienced significantly prolonged allograft function compared with that of the TS-1/22-treated (open circles) animals or the basiliximab/sirolimus-treated (asterisks) animals. TS-1/22 was discontinued on POD 35 (white arrow), and sirolimus was discontinued on POD 180 (black arrow). Statistical analysis using the log-rank test for graft survival among groups showed the superiority of combined therapy as compared with that of TS-1/22 alone $(P=0.0082)$ and basiliximab and sirolimus $(P=0.0046)$. (C-E) Representative FBG graphs of (C) combined TS-1/22 plus basiliximab and sirolimus, (D) TS-1/22 alone, and (E) basiliximab and sirolimus islet recipients show immediate resolution of hyperglycemia on the day of transplant, followed by variable periods of euglycemia. Again, TS-1/22 was discontinued on POD 35 (white arrow), and sirolimus was discontinued on POD 180 (black arrow). Individual group member survival times (in days) are listed in the top right corner of each corresponding representative graph.

cryptovirus (rhLCV); these 3 pathogens are the rhesus homologs of human cytomegalovirus, BK virus, and Epstein-Barr virus, respectively. Group 1 and group 2 monkeys did not experience any SV40 reactivation, while rhLCV remained unchanged from pretransplant levels. RhCMV viremia was also controlled and maintained at levels not associated with clinical disease, using standard clinical antiviral prophylaxis. Two group 2 animals exhibited a single instance of mild rhCMV reactivation above the clinically meaningful threshold but were easily managed with ganciclovir (data not shown).

The growth of captive NHPs is deemed a sensitive indicator of health in adolescent rhesus macaques (26). Notwithstanding the expected weight loss in the immediate perioperative period secondary to diabetes induction and transplantation, group 1 and 2 animals exhibiting prolonged islet allograft survival experienced excellent weight retention and growth (Figure 10). Pathologic analysis of all islet recipients at necropsy was grossly and microscopically unremarkable for any adverse process related to the immunosuppressive regimens used in this study.

\section{Discussion}

Since the discovery of LFA-1 as a surface molecule that plays a critical role in $\mathrm{T}$ cell-mediated immune responses, its potential as a therapeutic target has been evident. While targeting LFA-1 has been applied to treat autoimmunity, it has yet to be adopted for use in transplantation. In this report, we observed that short-term LFA-1specific induction therapy, together with belatacept or basiliximab and sirolimus, considerably prolonged islet allograft survival in rhesus monkeys, with $40 \%$ of recipients achieving more than 1-year 

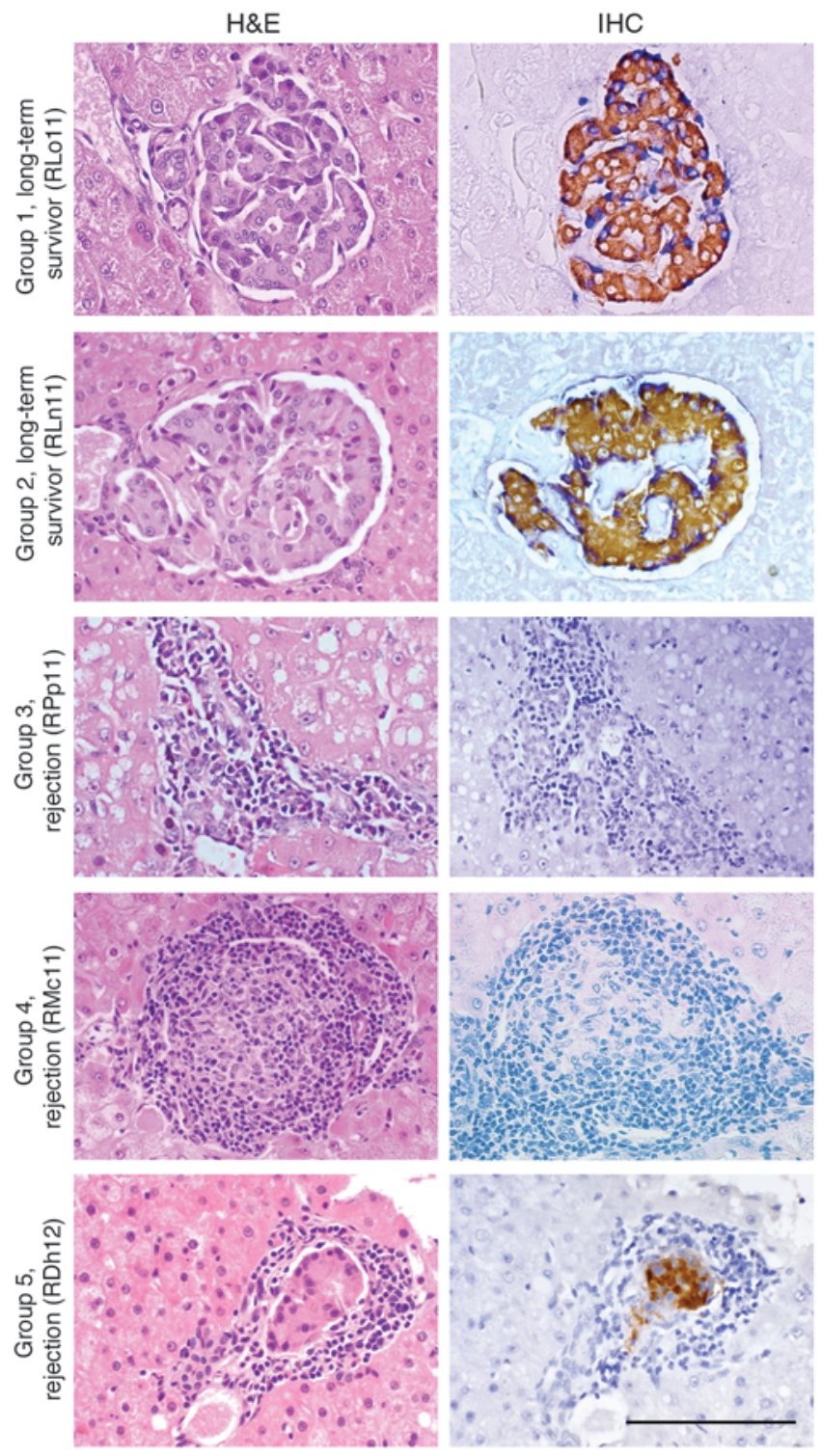

rejection-free insulin independence. Though the majority of group 1 animals developed alloantibodies, combination TS-1/22 and belatacept prevented DSA formation in all recipients, regardless of rejection or long-term graft function.

Overall, the anti-LFA-1-based regimens evaluated in this study were very well tolerated. Treated animals gained weight and controlled opportunistic pathogens. As mentioned, 1 TS-1/22-treated animal with allograft function required euthanasia on POD 17, secondary to weight loss, but in view of the circumstances surrounding its experimental course and the weight retention, preservation of protective immunity, and negative necropsy findings observed in the other group 1 and 2 animals, this recipient may have succumbed from STZ-related complications, independent of LFA-1-based immunosuppression.

Of the anti-LFA-1-treated animals reaching 1-year graft survival, the two group 1 recipients achieved a state of functional tolerance. They remained insulin independent for more than 6 months after withdrawal of all immunosuppression (Figure 4), a result not previously observed in NHP models of islet transplantation using non-

\section{Figure 5}

Long-term survivor islet allografts remained rejection free. Representative histologic liver sections harvested at necropsy from animals in each treatment group are shown. Sections were stained using standard H\&E (left column) and immunohistochemical (IHC; right column) methods. Group 1 and 2 long-term survivors had pristine donor islets embedded in the liver, free of any lymphocytic infiltrates and strong insulin (brown) and glucagon (blue) staining. In contrast, all group 3, 4 , and 5 islet recipients exhibited dense lymphocytic infiltration and destruction of transplanted islets, with little to no insulin or glucagon staining, characteristic of allograft rejection. Scale bar: $100 \mu \mathrm{m}$.

depleting regimens. These long-term survivors could not be rechallenged with secondary grafts to test for donor-specific tolerance, because allograft function beyond the discontinuation of maintenance therapy was unexpected, and donor tissue had not been preserved for this purpose. After transplant, MLCs performed during this period of operational tolerance were hyporesponsive but reactive relative to pretransplant proliferation (data not shown). The continued presence of donor-specific $T$ cell reactivity implies that complete deletional tolerance was not the mechanism of graft survival under this regimen. This finding, in conjunction with the observed formation of alloantibodies in 1 of the 2 long-term survivors, suggested impending graft failure, not tolerance, as the production of DSAs very often precedes rejection. One might speculate that the use of sirolimus may have induced Treg-mediated survival, as mTOR inhibition has been shown to promote long-term engraftment in allotransplantation by various mechanisms, including preservation of Treg-dependent immunoregulatory networks (27). While we did not examine the effect of our LFA-1-based regimens on Tregs, further investigation is warranted.

Signal 2 blockade alone is insufficient to protect transplanted tissues in some experimental models. Costimulation blockaderesistant rejection has been observed in stringent murine models, NHPs, and humans. In mice, the mechanisms of costimulation blockade resistance have been shown to involve discreet populations of non-memory $\mathrm{CD}^{+} \mathrm{T}$ cells $(28,29)$, with graft survival requiring $\mathrm{CD}^{+} \mathrm{T}$ cell deletion in some instances $(30)$. In fact, the use of antibodies against LFA- 1 to complement costimulatory regimens has proven effective in these systems $(29,31,32)$, validating the use of LFA-1-specific agents to address unengaged targets like resistant $\mathrm{CD}^{+} \mathrm{T}$ cells.

Numerous studies have implicated donor-reactive memory T cells in costimulation blockade-independent rejection (4). These cells derive from previous antigen exposure, heterologous immunity, or homeostatic proliferation $(5,33)$ and acquire phenotypes distinct from their naive counterparts. $T_{M}$ cells have reduced requirements for costimulation and display increased levels of adhesion molecules. However, the potential for therapeutic manipulation of this phenotype with biologic agents has not been extensively explored. We recently showed that CD2-directed elimination of $T_{M}$ cells in combination with a costimulation blockade-based regimen prevents renal allograft rejection in NHPs (7). In this study, we have shown that rhesus $\mathrm{T}$ cell repertoires consist of CD11 $\mathrm{a}^{\text {hi }} \mathrm{T}_{\mathrm{M}}$ cells, inclusive of CD11 $\mathrm{a}^{\text {hi }} \mathrm{T}_{\mathrm{EM}}$ cells lacking CD28, and CD28+CD11a ${ }^{\text {lo }}$ $\mathrm{T}_{\mathrm{N}}$ cells (Figure 1). Additionally, we determined that LFA-1 is upregulated on alloproliferative and cytokine-secreting T cells and that TS-1/22 was capable of suppressing the acquisition of these effector functions in response to antigen in vitro. Thus, while both belatacept and anti-LFA-1 therapy have the potential to prevent 

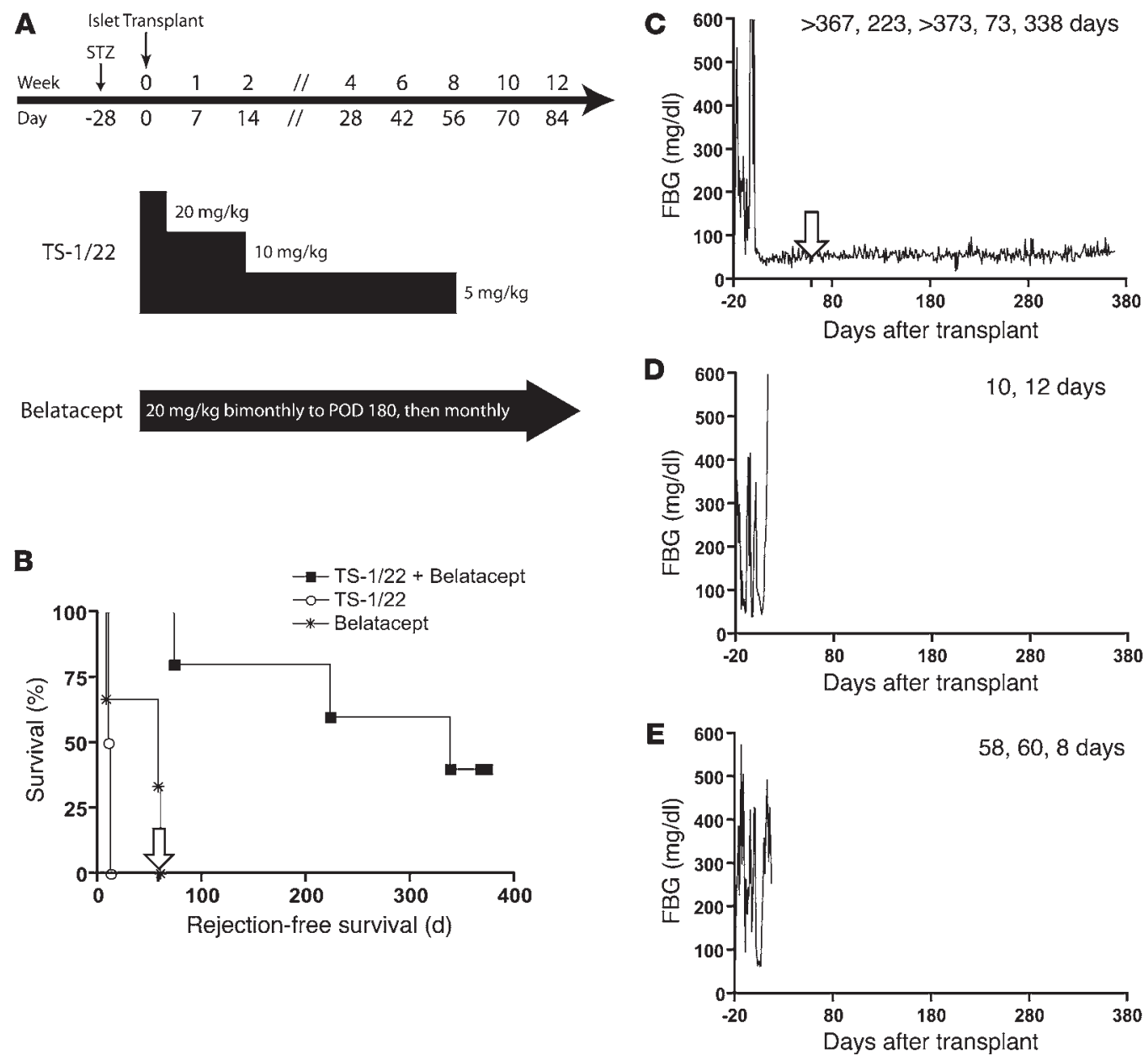

\section{Figure 6}

Combined LFA-1/CD28 blockade extends islet allograft survival. (A) The experimental design is shown. Diabetic rhesus monkeys were transplanted with allogeneic islets and received TS-1/22 induction alone, belatacept maintenance monotherapy, or a combination of both agents. After islet engraftment, rejection was defined as a FBG of more than $130 \mathrm{mg} / \mathrm{dl}$ on 2 consecutive days. (B) Recipients treated with TS-1/22 plus belatacept (filled squares) experienced significantly prolonged allograft function compared with that of TS-1/22-treated (open circles) animals or belatacept-treated (asterisks) animals. TS-1/22 was discontinued on POD 59 (white arrow). Statistical analysis using the log-rank test for graft survival among groups showed the superiority of the combined therapy as compared with TS-1/22 $(P=0.0082)$ and belatacept monotherapy $(P=0.0042)$. (C-E) Representative FBG graphs of (C) combined TS-1/22 plus belatacept, (D) TS-1/22 alone, and (E) belatacept monotherapy islet recipients show immediate resolution of hyperglycemia on the day of transplant, followed by variable periods of euglycemia (the representative TS-1/22 monotherapy graph is the same as in Figure 4D). Again, TS-1/22 was discontinued on POD 59 (white arrow). Individual group member survival times (in days) are listed in the top right corner of each corresponding representative graph.

naive alloimmune responses (Figure 2), only anti-LFA-1 attenuated the response of preexisting donor-reactive $T$ cells that expressed high levels of LFA-1 (Figure 3).

Consistent with this hypothesis, we observed that TS- $1 / 22$ induction plus belatacept maintenance led to $40 \% 1$-year graft survival. TS-1/22 achieved CD11a receptor occupancy of naive and memory $\mathrm{T}$ cell compartments alike (Figure 7 ), causing a universal lymphocytosis of circulating subsets that corroborates the ability of TS- $1 / 22$ to bind costimulation-resistant CD28-CD11 $\mathrm{a}^{\text {hi }} \mathrm{T}_{\mathrm{EM}}$ cells. Targeting LFA- 1 as an adjunct to belatacept-mediated CD28 blockade seemingly antagonizes $T_{N}$ cells, while covering signal 2 -independent anti-donor $\mathrm{T}_{\mathrm{M}}$ cells.

Because LFA-1 has varied immunologic functions, the mechanism by which its blockade protects allografts is unclear. It is accepted that successful targeting of LFA-1 does not require depletion and that its blockade entraps lymphocytes in the blood stream, preventing $\mathrm{T}$ cell access to secondary lymphoid organs or donor tissue to produce an immune response (34). However, this phenomenon can only partially explain the beneficial effect of anti-LFA-1 on graft survival, considering a transient lymphocytosis and eventual $\mathrm{T}$ cell infiltration of transplanted tissue, as observed in this study and others (35). Furthermore, in our model islets were intravascularly transplanted, bypassing transendothelial migration required for activated $\mathrm{T}$ cell-antigen contact and recognition prior to engraftment into the liver. Based on these observations and our in vitro results, we posit that therapeutic LFA-1 blockade is more likely to interfere with optimal antigen presentation and priming of naive $T$ cells via adequate synapse formation and costimulatory activation and inhibit resistant populations of $\mathrm{T}_{\mathrm{M}}$ cells than solely by the mechanism of immune ignorance. 
A

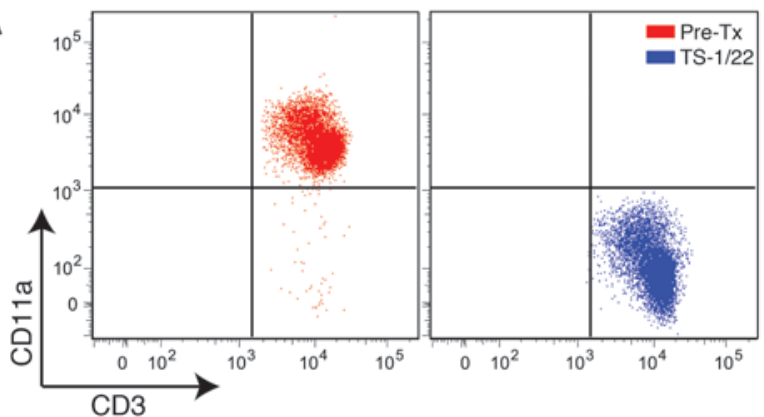

B

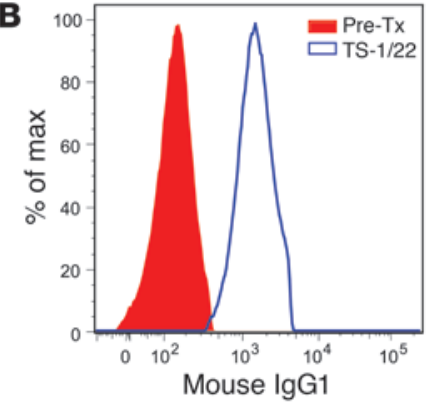

C

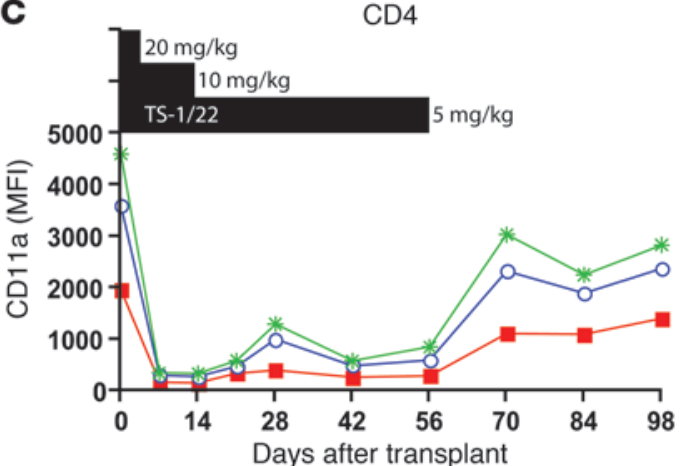

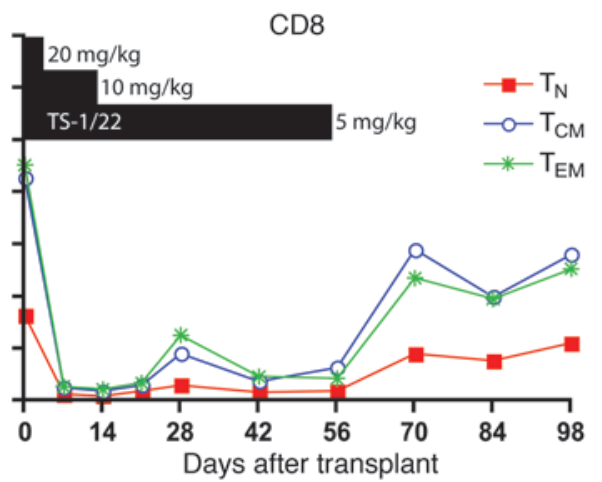

Figure 7

TS-1/22 achieves LFA-1/CD11a receptor occupancy in vivo. Pharmacodynamic monitoring of serially sampled peripheral lymphocytes from anti-LFA-1-treated animals was done using PFC. A fluorochromeconjugated antibody competitive with TS-1/22 for CD11a was used to determine the degree of LFA-1 receptor occupancy. (A) Representative PFC plots of recipient CD3 ${ }^{+}$lymphocytes before transplant (PreTx, red) and while on TS-1/22 (blue) are shown. T cell CD11a was highly detectable before transplant and transitioned to undetectable levels during anti-LFA-1 treatment as TS-1/22 occupied LFA-1. (B) Staining $\mathrm{CD}^{+}$lymphocytes for the mouse IgG1 tail of TS-1/22 showed therapeutic antibody coating target cell surfaces. (C) $\mathrm{CD}^{+}$and $C D 8^{+}$subsets $\left(\mathrm{T}_{\mathrm{N}}, \mathrm{T}_{\mathrm{CM}}\right.$, and $\mathrm{T}_{\mathrm{EM}}$ ) experienced equivalent dose-dependent $\mathrm{CD} 11 \mathrm{a}$ receptor occupancy, despite differential expression at baseline and after the discontinuation of TS-1/22 (dosing is depicted by the black bars).

One limitation of this study is that the primate model used does not involve overcoming the barrier of possible recurrent autoimmunity in type 1 diabetics undergoing islet transplantation. However, our results indicating that LFA-1 blockade suppresses $\mathrm{T}_{\mathrm{M}}$ cells suggest that targeting LFA-1 may be effective at inhibiting autoreactive $\mathrm{T}$ cell recall responses. In support of this possibility, LFA-1-specific therapy is effective for autoimmune disease in humans, and targeting LFA- 1 has been shown to prevent rejection of allogeneic islets in NOD mice with preexisting autoimmunity (36). Thus, LFA-1specific inhibition of autoreactive $T$ cells may limit autoimmune destruction of transplanted islets in type 1 diabetics.

Since FDA approval in 2003, the LFA-1-specific mAb efalizumab has been used for the treatment of plaque psoriasis (12). In April 2009, efalizumab was voluntarily withdrawn from the US market by its manufacturer in response to an association with a rare but potentially lethal condition known as progressive multifocal leukoencephalopathy (PML). Postmarketing surveillance reported 3 confirmed cases and 1 possible case of PML out of approximately 46,000 treated patients (37), all occurring in subjects receiving efalizumab for more than 3 years. Though even rare occurrences of PML may make the risk-benefit profile of efalizumab inappropriate for the treatment of psoriasis, the risk might not exceed that of existing therapies used to prevent transplant rejection. For example, PML has been linked

\section{Methods}

\section{PFC analysis}

Extracellular staining. Surface staining was performed on peripheral whole blood isolated from rhesus macaques. After red blood cell lysis, cells were suspended in PBS and incubated with surface marker-specific antibodies, washed with $2 \% \mathrm{FBS} / \mathrm{PBS}$, and processed on the LSR II (BD Biosciences). Fluorochrome-conjugated antibodies against CD3, CD4, CD8, CD11a, CD20, CD95, mouse IgG (all from BD Biosciences), and CD28 (eBioscience) were used. Data were analyzed with FlowJo software (Tree Star).

Intracellular cytokine staining. Monkey PBLs were stimulated with alloantigen for 6 hours (see MLCs) or VV for 12 hours (see Vaccinia-specific effector response assay) in the presence of brefeldin $\mathrm{A}$, which was added for the last 6 hours of culture only. Cells were then washed and surface stained as described above at $4^{\circ} \mathrm{C}$. Intracellular cytokine staining was then done according to manufacturer instructions (BD Biosciences). Cytokine antibody cocktails contained IFN- $\gamma$ and TNF- $\alpha$. Cells were processed on the LSR II and analyzed with FlowJo software.

\section{MLCs}

Recipient and donor PBLs isolated from rhesus whole blood were designated "responders" and "stimulators," respectively. Responder PBLs were depleted of APCs by magnetic cell sorting using MACS LD columns and 

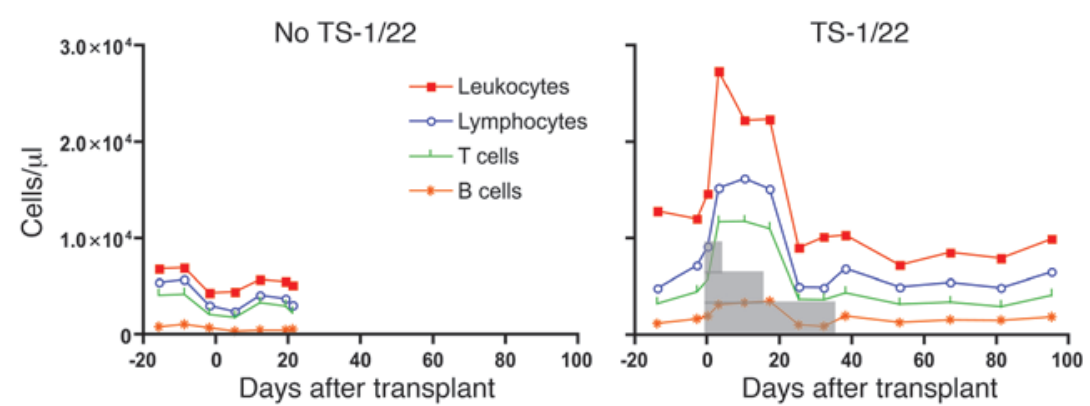

Figure 8

TS-1/22 induces a peripheral lymphocytosis. Complete blood counts and PFC were serially performed on all islet allograft recipient peripheral blood. Animals receiving anti-LFA-1 therapy experienced an increase in the absolute number of circulating leukocytes, including $T$ and $B$ cells. Longitudinal blood counts on an anti-LFA-1-treated group 1 recipient compared with a group 4 animal not receiving LFA-1-specific therapy represent this dose-dependent TS-1/22-associated lymphocytosis. Counts normalized to pretransplant levels after TS-1/22 discontinuation (dosing is depicted by the gray bars).

HLADR and CD20 beads according to package inserts (Miltenyi Biotec). Responders were then labeled with $10 \mu \mathrm{M}$ CFSE, while non-CFSE-labeled responders and stimulators were $\gamma$-irradiated to ensure unidirectional proliferation. Responder-stimulator pairs, combined at a 1:2 ratio, were cultured for 6 hours for intracellular cytokine assays or 5 days for proliferation assays in 10\% FBS/RPMI. Dose-effect analyses of proliferation inhibition by TS-1/22 and/or belatacept were done at indicated concentrations (Figure 2, C and D). At experimental end points, cells were surface stained for CD3, CD4, CD8, and CD11a as described for analysis by PFC.

\section{Vaccinia-specific effector response assay}

PBLs isolated from rhesus macaques vaccinated with VV by scarification (Dryvax, Wyeth) and boosted with MVA were incubated 12 hours with VV at an MOI of 1. Brefeldin A was added for the last 6 hours of culture to allow for the assessment of cytokine production (see Intracellular cytokine staining). Dose-effect analysis of effector cell inhibition by TS-1/22 and other bio- logic agents was done at 1,10 , and $50 \mu \mathrm{g} / \mathrm{ml}$. Controls consisted of PBLs plus VV without TS-1/22, PBLs alone, and PBLs plus staphylococcal enterotoxin B.

\section{NHPs}

Captive bred rhesus macaques used as donors (weight range, $10-20 \mathrm{~kg}$ ) and recipients (weight range, $3-5 \mathrm{~kg}$ ) were obtained from Yerkes National Primate Research Center. All recipients were specific pathogen-free. Donor-recipient pairs were class I and/or class II MHC mismatched and alloreactive by MLCs. All experiments were conducted in accordance with the principles set forth in the Guide for the Care and Use of Laboratory Animals (NIH publication no. 85-23. Revised 1985) and approved by Emory University's IACUC.

\section{Diabetes induction}

Diabetes was chemically induced by STZ (Zanosar, Teva Parenteral Medicines). Three initial recipients (RWi11, RVh11, and RMc11) were dosed at $1,600 \mathrm{mg} / \mathrm{m}^{2}$ i.v., but observed toxicity in RWi11 and monkeys in other concurrent studies prompted subsequent usage at $1,250 \mathrm{mg} / \mathrm{m}^{2}$. Four historical control animals (RQz6, RIb7, RIt7, and RKu7) underwent duodenal-sparing total pancreatectomies for diabetes induction 2-4 weeks prior to transplant, as previously described $(41,42)$.

\section{Donor pancreatectomy}

Donor pancreatectomies were performed under general anesthesia 1 day prior to transplantation. Via a midline laparotomy incision, the lesser sac was entered and the pancreatic tail and spleen were mobilized, the short gastric vessels were divided, and the pancreatic body was dissected free. The head and neck were then partially mobilized, heparin was administered, the infrarenal aorta was cannulated, and the animal was exsanguinated. Cold saline slush was immediately packed around the pancreas. The common bile and pancreatic ducts were ligated, and the remainder of the pancreas was resected.

\section{Figure 9}

TS-1/22 plus belatacept prevents DSA formation. Donor lymphocytes were incubated with corresponding group 1 (TS-1/22, basiliximab, and sirolimus) and 2 (TS-1/22 and belatacept) islet recipient sera to test for the presence of alloantibodies using PFC. Before transplant and terminal after transplant (Post-Tx) time points are depicted. (A and B) Three out of four evaluable group 1 recipients formed allospecific antibodies, as indicated by the increase in anti-donor IgG after transplant relative to before transplant values. One long-term survivor (RLo11) did not develop alloantibodies. (C and D) In contrast, DSAs were not detected in any group 2 recipients, irrespective of allograft rejection (RDp11, RNw11, and RHu11) or survival (RLn11 and RGm11).
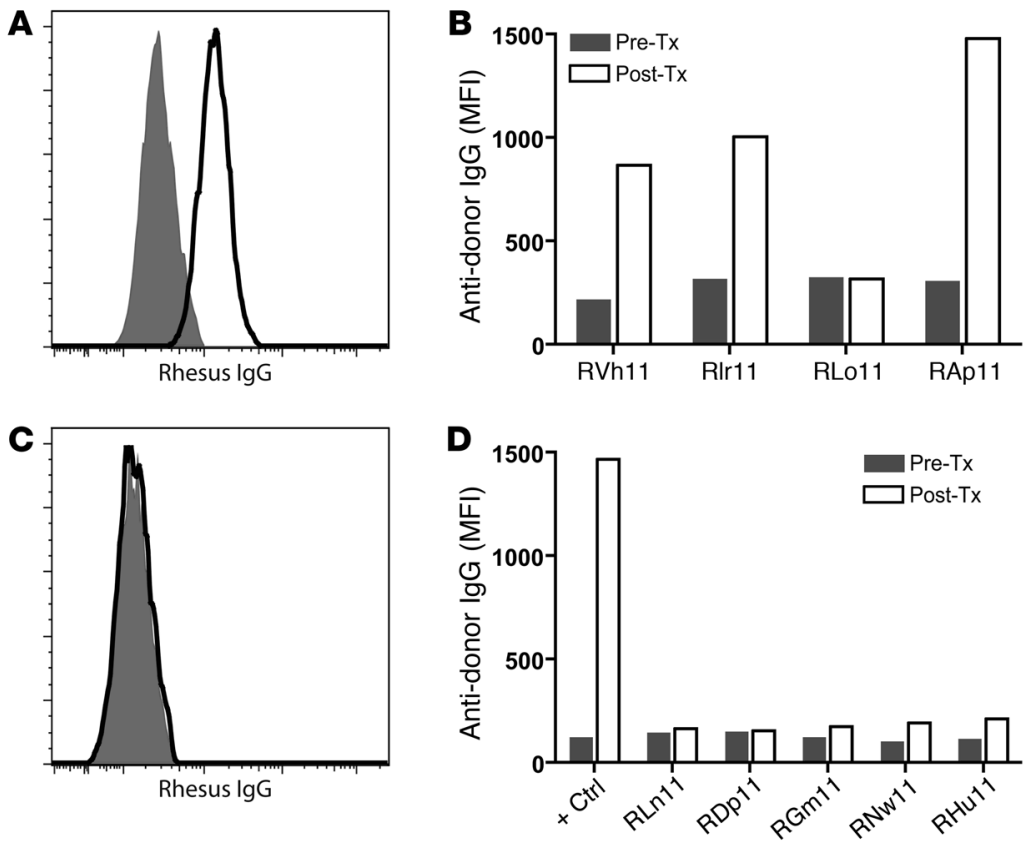

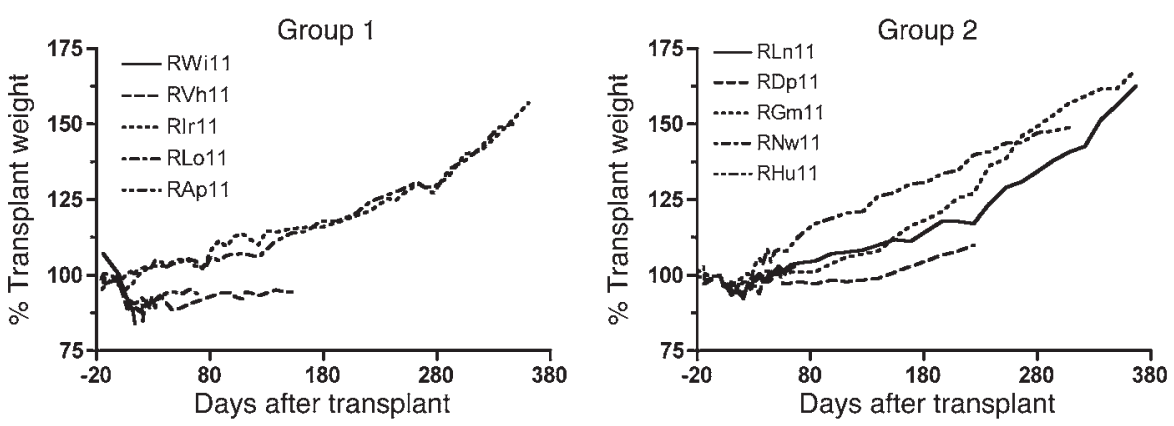

Figure 10

LFA-1-based regimens do not restrict NHP growth. Group 1 and 2 primates receiving TS-1/22 exhibited posttransplant weight retention and growth, following diabetes induction. Apart from one group 1 animal (RWi11) receiving high-dose STZ, observed weight loss was limited to the pretransplant period. Anti-LFA-1-treated animals resumed weight gain and growth relative to their weights at the time of transplant.

\section{Islet isolation}

Pancreatic islet isolation was achieved through minor modifications of the automated method for human islet isolation (43) using Liberase HI (0.71 $\mathrm{mg} / \mathrm{ml}$, Roche Applied Science). The pancreas was disrupted and the digest was purified on a Euroficoll gradient (Mediatech) and Cobe 2991 blood cell processor (CaridianBCT). Samples of the final islet preparation were stained with dithizone, counted according to size, and expressed as IEQs.

\section{Islet transplantation}

After overnight culture, islets were washed in transplant media and counted to determine the final number of IEQs available for transplant. They were then resuspended in media and supplemented with heparin. Under general anesthesia, the recipient abdomen was opened via a midline minilaparotomy incision, a mesenteric colic vein was cannulated with an angiocatheter, and the islet suspension was infused into the liver.

\section{Glucose management}

Fasting and non-FBG levels were measured with a glucometer daily via earstick. Insulin NPH (Novolin, Novo Nordisk) and glargine (Lantus, SanofiAventis) were administered 3 times daily to maintain a FBG of less than $300 \mathrm{mg} / \mathrm{dl}$ before transplant and after rejection. IVGTTs were performed before transplant to confirm diabetes and after transplant to monitor graft function. Fasting animals were given $1 \mathrm{ml} / \mathrm{kg}$ of $50 \%$ dextrose i.v., and blood samples were taken for glucose and C-peptide measurements at $0,10,30,60$, and 90 minutes. After transplant and islet engraftment, rejection was defined as FBG $>130 \mathrm{mg} / \mathrm{dl}$ on 2 consecutive days.

\section{Experimental groups and immunosuppression}

Five groups of diabetic rhesus macaques received different immunosuppressive regimens (Table 1 ). Group 1 received TS- $1 / 22$ i.v. on PODs 0 and 3 at $20 \mathrm{mg} / \mathrm{kg}$; on PODs 7, 10, and 14 at $10 \mathrm{mg} / \mathrm{kg}$; and on PODs 17, 21, $24,28,31$, and 35 at $5 \mathrm{mg} / \mathrm{kg}$; group 1 also received basiliximab on PODs 0 and $3(0.3 \mathrm{mg} / \mathrm{kg}$ i.v. $)$ and sirolimus once daily, which was initiated at 0.1 $\mathrm{mg} / \mathrm{kg}$ i.m. and titrated to achieve target trough levels of $5-15 \mathrm{ng} / \mathrm{ml}$ until discontinuation on POD 180, at which point survival was considered sufficient to determine TS- $1 / 22$ induction effective. Group 2 received TS- $1 / 22$ with an additional $5 \mathrm{mg} / \mathrm{kg}$ dose twice weekly until POD 59 to compensate for the absence of basiliximab induction and belatacept $(20 \mathrm{mg} / \mathrm{kg}$ i.v. $)$ on PODs $0,3,7$, and 14 , then every 2 weeks until POD 180, and then monthly thereafter without discontinuation, because we envisioned it as a more clinically relevant maintenance agent. Group 3 received single-agent therapy

\section{Viral prophylaxis and monitoring}

All animals were prophylaxed while on immunosuppression, depending on the intensity of therapy. Oral valganciclovir (Valcyte, Roche) served as basal prophylaxis, given at $60 \mathrm{mg}$ once daily, and cidofovir (Vistide, Gilead) was given i.v. once weekly during more intensive therapy. At times of meaningful viral reactivation, animals were treated with ganciclovir (Cytovene, Roche; $6 \mathrm{mg} / \mathrm{kg}$ i.m.) twice daily until resolution of viremia. All antiviral agents were purchased from the Emory University Hospital pharmacy.

Monitoring islet recipients for rhCMV, SV40, and rhLCV was done by periodically testing whole blood by real-time PCR using TaqMan chemistry and reagents from Applied Biosystems. Amplification and analyses were done on a model 7900HT Sequence Detection System (Applied Biosystems). RhCMV primers and probe amplified a 108-bp sequence (44). Sequences were as follows: forward primer, GTTTAGGGAACCGCCATTCTG; reverse primer, GTATCCGCGTTCCAATGCA; and TaqMan probe, 6FAM-TCCAGCCTCCATAGCCGGGAAGG-TAMRA. SV40 primers and probe were a modification of those described by Shi et al. and amplified a 130-bp sequence from the large $\mathrm{T}$ antigen gene (45). Sequences were as follows: forward primer, GTCTTCTACCTTTCTCTTCTT; reverse primer, GGAGCAGTGGTGGAA; and TaqMan probe, 6FAM-TGGAGGAGTAGAAGTTTGAGAGTCA-TAMRA. LCV primers were designed with Primer Express software (Applied Biosystems), using the sequence from NCBI (NC_006145) containing the rhesus EBER1 gene (46). Sequences were as follows: forward primer, GGAGGAGATGAGTGTGACTTAATTCA; reverse primer, TGAACCGAAGAGAGCAGAAACC; and TaqMan probe, 6FAM-GGGACTGTCCAAACTTTTAGCAGC-TAMRA. All primers were purchased from Sigma-Aldrich.

\section{DSA detection}

Isolated PBLs from donor whole blood were blocked with goat IgG (Jackson ImmunoResearch Laboratories Inc.) and then incubated with serial recipient sera. Donor cells were then washed with $2 \%$ FBS/PBS, incubated with FITClabeled goat anti-monkey IgG (KPL), washed again, and analyzed using PFC.

\section{Histology}

At necropsy, recipient tissue specimens were fixed in $10 \%$ formalin and processed in paraffin blocks for H\&E staining and immunohistochemical analysis. Tissue sections were labeled with antigen-specific primary antibodies and then visualized using the LSAB+-labeled Streptavidin-Biotin Kit (Dako). Primary antibodies were specific for insulin (Sigma-Aldrich), C4d (ARP), glucagon, CD3, CD20, and CD68 (Dako). 


\section{Statistics}

Islet allograft survival curves were created using the product limit method of Kaplan and Meier, and the log-rank (Mantel-Haenszel) test was used to compare survival among experimental groups. A $P$ value of less than 0.05 was considered statistically significant.

\section{Acknowledgments}

The Juvenile Diabetes Research Foundation (4-2005-1328) primarily funded this work, with additional support from the NIH (2U19-AI051731 and N01-AI50025). The NHP Reagent Resource (NIAID HHSN272200900037C) provided assistance with antibody production for in vitro assays and in vivo animal studies.
The authors would like to thank Bristol-Myers Squibb for the provision of belatacept and are indebted to Yerkes National Primate Research Center staff and personnel for the outstanding care afforded to the NHPs used in this study.

Received for publication June 1, 2010, and accepted in revised form September 22, 2010.

Address correspondence to: Christian P. Larsen, Emory University Hospital, 1364 Clifton Road, NE, Suite B206, Atlanta, Georgia 30322, USA. Phone: 404.727.5800; Fax: 404.727.4716; E-mail: clarsen@emory.edu.
1. Bretscher P, Cohn M. A theory of self-nonself discrimination. Science. 1970;169(950):1042-1049.

2. Lafferty KJ, Cunningham AJ. A new analysis of allogeneic interactions. Aust J Exp Biol Med Sci. 1975;53(1):27-42.

3. Mescher MF, et al. Signals required for programming effector and memory development by CD8+ T cells. Immunol Rev. 2006;211:81-92.

4. Valujskikh A, Li XC. Frontiers in nephrology: T cell memory as a barrier to transplant tolerance. J Am Soc Nephrol. 2007;18(8):2252-2261.

5. Adams AB, et al. Heterologous immunity provides a potent barrier to transplantation tolerance. J Clin Invest. 2003;111(12):1887-1895.

6. Ford ML, Kirk AD, Larsen CP. Donor-reactive T-cell stimulation history and precursor frequency: barriers to tolerance induction. Transplantation. 2009;87(9 suppl):S69-S74.

7. Weaver TA, et al. Alefacept promotes co-stimulation blockade based allograft survival in nonhuman primates. Nat Med. 2009;15(7):746-749.

8. Davignon D, Martz E, Reynolds T, Kurzinger K, Springer TA. Lymphocyte function-associated antigen 1 (LFA-1): a surface antigen distinct from Lyt2,3 that participates in T lymphocyte-mediated killing. Proc Natl Acad Sci U S A. 1981;78(7):4535-4539.

9. Nicolls MR, Gill RG. LFA-1 (CD11a) as a therapeutic target. Am J Transplant. 2006;6(1):27-36.

10. Scholer A, Hugues S, Boissonnas A, Fetler L, Amigorena S. Intercellular adhesion molecule-1dependent stable interactions between $\mathrm{T}$ cells and dendritic cells determine CD8 $+\mathrm{T}$ cell memory. Immunity. 2008;28(2):258-270.

11. Ford ML, Larsen CP. Translating costimulation blockade to the clinic: lessons learned from three pathways. Immunol Rev. 2009;229(1):294-306.

12. Lebwohl M, et al. A novel targeted T-cell modulator, efalizumab, for plaque psoriasis. $N$ Engl J Med. 2003;349(21):2004-2013.

13. Vincenti F, et al. A phase I/II randomized openlabel multicenter trial of efalizumab, a humanized anti-CD11a, anti-LFA-1 in renal transplantation. Am J Transplant. 2007;7(7):1770-1777.

14. Turgeon NA, et al. Experience with a novel efalizumab-based immunosuppressive regimen to facilitate single donor islet cell transplantation. Am J Transplant. 2010;10(9):2082-2091.

15. Berlin PJ, Bacher JD, Sharrow SO, Gonzalez C, Gress RE. Monoclonal antibodies against human $\mathrm{T}$ cell adhesion molecules--modulation of immune function in nonhuman primates. Transplantation. 1992;53(4):840-849.

16. Poston RS, et al. Effects of humanized monoclonal antibody to rhesus CD11a in rhesus monkey cardiac allograft recipients. Transplantation. 2000; 69(10):2005-2013.

17. Sanchez-Madrid F, et al. Three distinct antigens associated with human T-lymphocyte-mediated cytolysis: LFA-1, LFA-2, and LFA-3. Proc Natl Acad Sci US A. 1982;79(23):7489-7493.
18. Krensky AM, Sanchez-Madrid F, Robbins E, Nagy JA, Springer TA, Burakoff SJ. The functional significance, distribution, and structure of LFA-1, LFA-2, and LFA-3: cell surface antigens associated with CTL-target interactions. J Immunol. 1983; 131(2):611-616.

19. Pitcher CJ, et al. Development and homeostasis of $\mathrm{T}$ cell memory in rhesus macaque. J Immunol. 2002;168(1):29-43.

20. Harari A, Dutoit V, Cellerai C, Bart PA, Du Pasquier RA, Pantaleo G. Functional signatures of protective antiviral T-cell immunity in human virus infections. Immunol Rev. 2006;211:236-254.

21. Krentz AJ, Wheeler DC. New-onset diabetes after transplantation: a threat to graft and patient survival. Lancet. 2005;365(9460):640-642.

22. Barber DF, Faure M, Long EO. LFA-1 contributes an early signal for NK cell cytotoxicity. J Immunol. 2004;173(6):3653-3659.

23. Rutigliano JA, Johnson TR, Hollinger TN, Fischer JE, Aung S, Graham BS. Treatment with antiLFA-1 delays the CD8+ cytotoxic-T-lymphocyte response and viral clearance in mice with primary respiratory syncytial virus infection. J Virol. 2004; 78(6):3014-3023

24. Larsen CP, et al. Long-term acceptance of skin and cardiac allografts after blocking CD40 and CD28 pathways. Nature. 1996;381(6581):434-438.

25. Larsen CP, Knechtle SJ, Adams A, Pearson T, Kirk AD. A new look at blockade of T-cell costimulation: a therapeutic strategy for long-term maintenance immunosuppression. Am J Transplant. 2006;6(5 pt 1):876-883.

26. Catchpole HR, Van Wagenen G. Physical growth of the Rhesus monkey (Macaca mulatta). Am J Phys Anthropol. 1956;14(2):245-273.

27. Zheng XX, Sanchez-Fueyo A, Sho M, Domenig C, Sayegh MH, Strom TB. Favorably tipping the balance between cytopathic and regulatory $\mathrm{T}$ cells to create transplantation tolerance. Immunity. 2003; 19(4):503-514.

28. Trambley J, et al. Asialo GM1(+) CD8(+) T cells play a critical role in costimulation blockaderesistant allograft rejection. J Clin Invest. 1999; 104(12):1715-1722.

29. Wang Y, Gao D, Lunsford KE, Frankel WL, Bumgardner GL. Targeting LFA-1 synergizes with CD40/CD40L blockade for suppression of both CD4-dependent and CD8-dependent rejection. Am J Transplant. 2003;3(10):1251-1258.

30. Iwakoshi NN, Mordes JP, Markees TG, Phillips NE, Rossini AA, Greiner DL. Treatment of allograft recipients with donor-specific transfusion and anti-CD154 antibody leads to deletion of alloreactive CD8+ $\mathrm{T}$ cells and prolonged graft survival in a CTLA4-dependent manner. J Immunol. 2000; 164(1):512-521.

31. Corbascio M, et al. CTLA4Ig combined with antiLFA-1 prolongs cardiac allograft survival indefinitely. Transpl Immunol. 2002;10(1):55-61.

32. Nicolls MR, Coulombe M, Beilke J, Gelhaus HC,
Gill RG. CD4-dependent generation of dominant transplantation tolerance induced by simultaneous perturbation of CD154 and LFA-1 pathways. J Immunol. 2002;169(9):4831-4839.

33. Wu Z, et al. Homeostatic proliferation is a barrier to transplantation tolerance. Nat Med. 2004; 10(1):87-92.

34. Vugmeyster Y, et al. Efalizumab (anti-CD11a)induced increase in peripheral blood leukocytes in psoriasis patients is preferentially mediated by altered trafficking of memory CD8+ T cells into lesional skin. Clin Immunol. 2004;113(1):38-46.

35. Nicolls MR, Coulombe M, Yang H, Bolwerk A, Gill RG. Anti-LFA-1 therapy induces long-term islet allograft acceptance in the absence of IFN-gamma or IL-4. J Immunol. 2000;164(7):3627-3634.

36. Berney T, et al. The effect of simultaneous CD154 and LFA-1 blockade on the survival of allogeneic islet grafts in nonobese diabetic mice. Transplantation. 2003;76(12):1669-1674.

37. FDA Public Health Advisory Updated Safety Information about Raptiva (efalizumab). U.S. Food and Drug Administration Web site. http:// www.fda.gov/Drugs/DrugSafety/PublicHealth Advisories/ucm 110605.htm. Updated February 19, 2009. Accessed May 29, 2010.

38. Neff RT, et al. Progressive multifocal leukoencephalopathy and use of mycophenolate mofetil after kidney transplantation. Transplantation. 2008; 86(10):1474-1478.

39. Allison M. PML problems loom for Rituxan. Nat Biotechnol. 2010;28(2):105-106.

40. Vincenti F, et al. A phase III study of belataceptbased immunosuppression regimens versus cyclosporine in renal transplant recipients (BENEFIT study). Am J Transplant. 2010;10(3):535-546.

41. Adams AB, et al. Calcineurin inhibitor-free CD28 blockade-based protocol protects allogeneic islets in nonhuman primates. Diabetes. 2002;51(2):265-270.

42. Adams AB, et al. Development of a chimeric antiCD40 monoclonal antibody that synergizes with LEA29Y to prolong islet allograft survival. J Immunol. 2005;174(1):542-550.

43. Ricordi C, Lacy PE, Finke EH, Olack BJ, Scharp DW. Automated method for isolation of human pancreatic islets. Diabetes. 1988;37(4):413-420.

44. Barry PA, Alcendor DJ, Power MD, Kerr H, Luciw PA. Nucleotide sequence and molecular analysis of the rhesus cytomegalovirus immediate-early gene and the UL121-117 open reading frames. Virology. 1996;215(1):61-72.

45. Shi L, Ho J, Norling LA, Roy M, Xu Y. A real time quantitative PCR-based method for the detection and quantification of simian virus 40 . Biologicals. 1999;27(3):241-252.

46. Rao P, Jiang H, Wang F. Cloning of the rhesus lymphocryptovirus viral capsid antigen and EpsteinBarr virus-encoded small RNA homologues and use in diagnosis of acute and persistent infections. J Clin Microbiol. 2000;38(9):3219-3225. 